\title{
Probabilistic approach in the heavy rainfall modelling - is model verification needed?
}

\author{
Marcin Wdowikowski ${ }^{1, *}$, Bartosz Kaźmierczak ${ }^{2}$, and Katarzyna Wartalska ${ }^{2}$ \\ ${ }^{1}$ Institute of Meteorology and Water Management - National Research Institute, Podleśna Street 61, 01-673 Warsaw, Poland \\ ${ }^{2}$ Wrocław University of Science and Technology, Faculty of Environmental Engineering, Wyb. Wyspiańskiego 27, 50-370 Wrocław, \\ Poland
}

\begin{abstract}
The aim of this paper is an attempt to answer the question whether it is necessary to update the probabilistic model of heavy rainfall with the passage of time. Based on IMWM-NRI measurement data in Wroclaw, probabilistic models for data from 1960-2009 with data up to 2017 were compared. The analysis showed that intense rainfall recorded in recent years can significantly affect the course of the depthduration-frequency (DDF) model.
\end{abstract}

\section{Introduction}

Secure sewerage systems designing is intended to ensure a required water drainage standard, defined as the adaptation of the drainage system to receiving the maximum - forecasted rainfall water streams occurring with a frequency equal to the allowable - socially acceptable - frequency of occurrence of a terrain surface flooding (Table 1). The current European standard EN 752 allows the frequency of sewerage system overflows to the rare repeatability of their occurrence: one time per 10 years - in case of rural areas and one time per 20, 30 or 50 years for urban areas - respective to the spatial development type. The quoted European standard recommends, for the designing of drainage areas, the following rainfall occurrence frequencies: once a year in case of rural areas, and once in 2, 5 or 10 years for municipal areas, whereby there can be no overload in the operation of the gravity systems - work under pressure. It, therefore, follows that, among others, the need to select the sewers for incomplete filling, namely with a capacity reserve in case of less frequent rainfall $[1,2]$.

The sizing of drainage or combined sewage systems in Poland presents difficulties resulting from the lack of a reliable precipitation model. Most often used model of Błaszczyk from 1954 lowers calculation results for rainfall intensities by $40 \%$, as shown in the paper, on the example of precipitation measured on the meteorological station IMWM-NRI (the Institute of Meteorology and Water Management - National Research Institute) in Wroclaw from the time span 1960-2009. This has consequences when sizing drainage areas according to the recommendations of European standard EN 752, directly affecting the higher frequency of occurrence of these unfavourable phenomena in Poland $[3,4]$.
Table 1. Recommended design rainfall frequency and acceptable spillage rates according to PN-EN 752: 2008.

\begin{tabular}{|c|c|c|}
\hline $\begin{array}{c}\text { C-year period for } \\
\text { theoretical } \\
\text { rainfall [1 event } \\
\text { per C year] }\end{array}$ & $\begin{array}{c}\text { Category of drainage } \\
\text { standard including } \\
\text { areas details }\end{array}$ & $\begin{array}{c}\text { Permissible } \\
\text { frequency of } \\
\text { spillage } \\
\text { [1 event per C } \\
\text { year] }\end{array}$ \\
\hline 1 & I. Rural areas & 10 \\
\hline 2 & $\begin{array}{c}\text { II. Urban areas } \\
\text { (inhabited areas) }\end{array}$ & 20 \\
\hline 5 & $\begin{array}{c}\text { III. City centers, } \\
\text { service, and industry } \\
\text { areas }\end{array}$ & 30 \\
\hline 10 & $\begin{array}{c}\text { IV. Underground } \\
\text { public transport and } \\
\text { communication } \\
\text { networks }\end{array}$ & 50 \\
\hline
\end{tabular}

The aim of the work is to verify the depth-durationfrequency (DDF) model of Kotowski and Kaźmierczak for Wroclaw (developed on the basis of measurement data from 1960-2009 [5]), extending the scope of measurement data to 2017 , in which several rainfall events with extremely high rainfall interval values occurred [6]. In the light of the increasingly frequent and intensified storms observed in recent years in the area of Wroclaw and Poland, the authors ask whether the probabilistic model needs updating.

\section{Materials and methods}

The meteorological station of the Institute of Meteorology and Water Management - National Research Institute in Wroclaw (southern west part of Poland) is a part of national measurement and observation network at hydrological and meteorological service. The station coordinates: 51-06 N, 16-54 E; terrain altitude: about $120 \mathrm{~m}$ above sea level. In this 
study, precipitation records from this IMWM-NRI meteorological station from 1960-2017 long-term period were used as a research material. To implement the measurement program, the station in Wroclaw uses standard equipment, typical for Polish National Hydrological and Meteorological Service synoptic stations, i.e. meteorological instruments connected to the MAWS - meteorological automatic weather station. The atmospheric precipitation measurement is carried out in parallel with the automatic SEBA rain gauge, which records the 1-minute rainwater and with the participation of a meteorological observer, which records 6 hour checksums and a daily sum using Hellmann's rain gauge. The collected measurement data is compared and verified after each reading $[5,7,8]$.

In the first stage of the research, an update of the sequence of the largest rainfall data in the assumed intervals of rainfall duration (from 5 to 4320 minutes) necessary for the construction of the probabilistic model was carried out. Figures from 1 to 4 present a comparison of the largest 50 elements acquired from the 1960-2009 data series and also from 1968-2017.

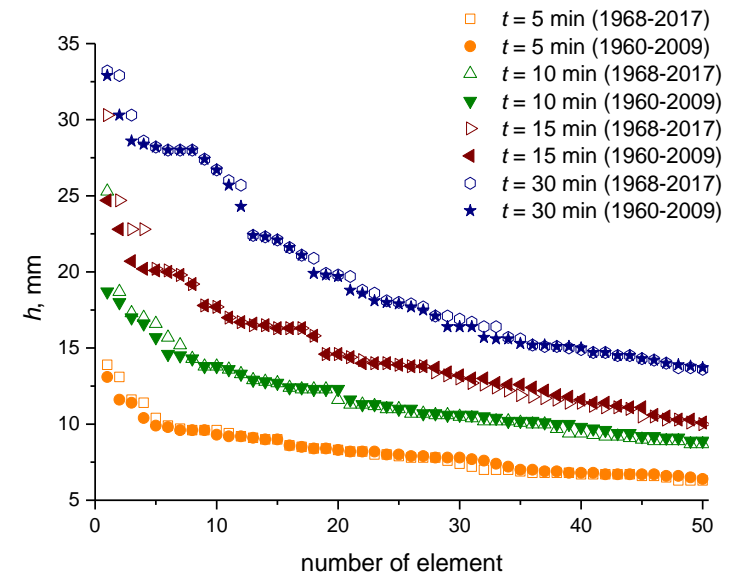

Fig. 1. Comparison of 5, 10, 15 and 30 minutes duration rainfall in the periods 1960-2009 and 1968-2017.

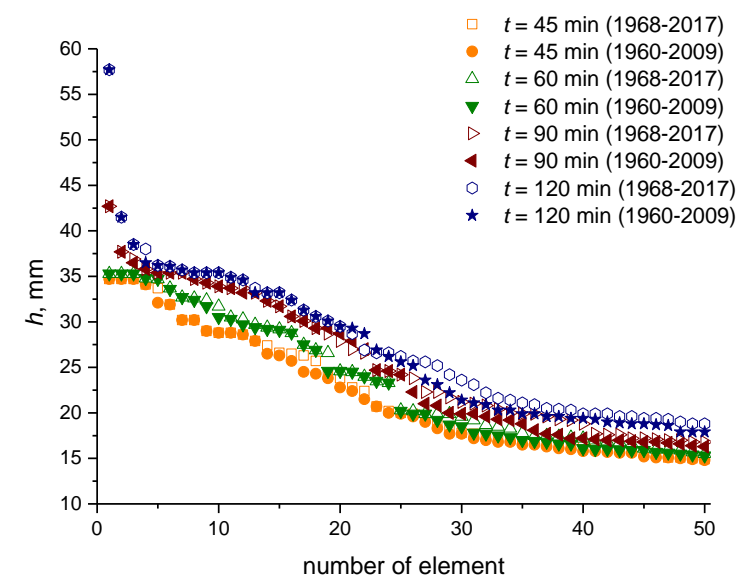

Fig. 2. Comparison 45, 60, 90 and 120 minutes duration rainfall in the periods 1960-2009 and 1968-2017.

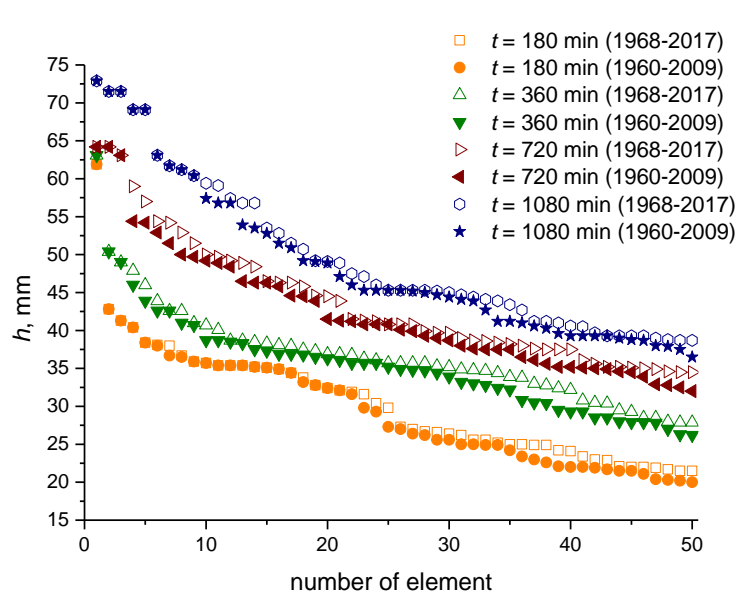

Fig. 3. Comparison of 180, 360, 720 and 1080 minutes duration rainfall in the periods 1960-2009 and 1968-2017.

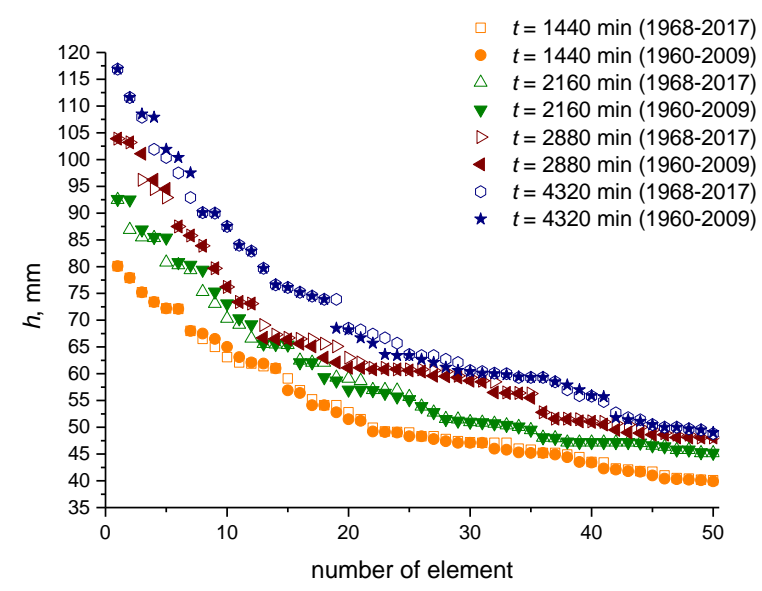

Fig. 4. Comparison of 1440, 2160, 2880 and 4320 minutes duration rainfall in the periods 1960-2009 and 1968-2017.

This simple comparison showed that the largest differences between the maximum precipitation values occur for the shortest duration. In the case of rainfall with the duration of 10 minutes, the highest recorded rainfall in the period 1960-2009 amounted to $18.7 \mathrm{~mm}$, while in the period 1968-2017 a value of $25.3 \mathrm{~mm}$ was recorded. Similarly, for 15 minutes duration rainfall maximum values of $24.7 \mathrm{~mm}$ and $30.3 \mathrm{~mm}$ were recorded, respectively for the periods 1960-2009 and 1968-2017.

The research in question was based on the methodology employed by Kotowski with the team, which assumes the following procedure for determining maximum rainfall with a specific duration and probability of occurrence [7-11]:

- isolation of the largest precipitation sums in intervals of 5 to 4320 minutes in an amount equal to the number of years of the data stream under investigation,

- in the resulting distribution series, non-binding assignment, the probability of empirical crossing,

- determining the estimators of parameters (shape, scale, location) of selected probability distributions 
with the maximum likelihood method (MLM) by numerically maximizing of the reliability function,

- analysis of matching theoretical distributions to measurement data using the following indicators: BIC - Bayesian Schwartz information criterion, AIC - Akaike information criterion, using the AndersonDarling test and the relative mean square residual error (RRMSE),

- the probabilistic model is constructed by the dependence of the probability distribution parameters as a function of time for the quantile of the random variable of the best fit distribution.

Using the above procedure, the generalized exponential distribution (GED) parameters were determined with the use of a maximum likelihood method [12] for the data from 1960-2009 and 19682017. Then, the theoretical precipitation heights with the specified duration and frequency of occurrence were calculated using the calculated parameters and the formula for this purpose [7, 12]:

$$
h(p)=\mu-\frac{1}{\beta} \ln \left(1-\left(1-\frac{1}{C}\right)^{\frac{1}{\alpha}}\right)
$$

The final step was to compare the results of 2 heavy rainfall probabilistic models for selected rainfall durations and also for selected empirical probabilities ( $C$-year return period).

\section{Results}

Based on rainfall data from both periods (1960-2009 and 1968-2017), the GED distribution parameters were calculated for all analyzed rainfall durations. The calculation results are shown in Table 2. The parameters were determined by the maximum likelihood method by numerically maximizing of the reliability function.

Table 2. Calculated parameters of the GED distribution.

\begin{tabular}{|c|c|c|c|c|c|c|}
\hline \multirow{3}{*}{$\boldsymbol{t}$, min } & \multicolumn{3}{|c|}{$1960-2009$} & \multicolumn{3}{c|}{$1968-2017$} \\
\cline { 2 - 7 } & $\boldsymbol{\alpha}$ & $\boldsymbol{\beta}$ & $\boldsymbol{\mu}$ & $\boldsymbol{\alpha}$ & $\boldsymbol{\beta}$ & $\boldsymbol{\mu}$ \\
\hline 5 & 1.222 & 0.628 & 6.4 & 0.776 & 0.447 & 6.3 \\
\hline 10 & 0.891 & 0.324 & 8.9 & 0.800 & 0.275 & 8.7 \\
\hline 15 & 1.444 & 0.268 & 10.0 & 0.975 & 0.205 & 10.0 \\
\hline 30 & 0.815 & 0.149 & 13.7 & 0.829 & 0.142 & 13.6 \\
\hline 45 & 0.736 & 0.116 & 14.8 & 0.804 & 0.118 & 14.9 \\
\hline 60 & 0.709 & 0.102 & 15.3 & 0.844 & 0.111 & 15.5 \\
\hline 90 & 0.712 & 0.090 & 16.3 & 0.684 & 0.088 & 16.8 \\
\hline 120 & 0.624 & 0.081 & 17.9 & 0.689 & 0.090 & 18.8 \\
\hline 180 & 0.911 & 0.098 & 20.0 & 0.755 & 0.094 & 21.5 \\
\hline 360 & 2.153 & 0.154 & 25.4 & 3.521 & 0.176 & 25.6 \\
\hline 720 & 1.468 & 0.120 & 31.8 & 0.708 & 0.087 & 34.5 \\
\hline 1080 & 1.274 & 0.095 & 36.4 & 0.659 & 0.070 & 38.7 \\
\hline 1440 & 0.817 & 0.068 & 39.9 & 0.840 & 0.069 & 40.1 \\
\hline 2160 & 0.735 & 0.058 & 45.2 & 0.682 & 0.057 & 45.2 \\
\hline 2880 & 0.526 & 0.041 & 48.1 & 0.705 & 0.048 & 48.1 \\
\hline 4320 & 0.848 & 0.043 & 49.0 & 0.901 & 0.044 & 48.8 \\
\hline
\end{tabular}

By substituting the parameters from Table 2 to Formula (1), the theoretical precipitation heights with given duration (from $t=5$ to $t=4320$ minutes) and frequency of occurrence (from $C=1$ to $C=50$ years) were calculated. The calculation results are presented in Table 3 for the data from 1960-2009 and in Table 4 for the data from 1968-2017.

Table 3. Theoretical rainfall amounts determined on the basis of measurement data from 1960-2009.

\begin{tabular}{|c|c|c|c|c|c|c|c|}
\hline$\underset{\text { min }}{t,}$ & UI & $\begin{array}{l}N \\
\text { II }\end{array}$ & $\begin{array}{l}\text { II } \\
\text { II }\end{array}$ & $\underset{\text { Un }}{\stackrel{\theta}{I I}}$ & 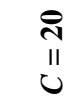 & $\begin{array}{l}\text { लि } \\
\text { II }\end{array}$ & $\begin{array}{l}\text { in } \\
\text { II } \\
0\end{array}$ \\
\hline 5 & 6.4 & 7.7 & 99.3 & 10.4 & 11.5 & 12.1 & 12.9 \\
\hline 10 & 8.9 & 10.8 & 13.6 & 15.7 & 17.8 & 19.0 & 20.6 \\
\hline 15 & 10.0 & 13.6 & 17.3 & 19.9 & 22.5 & 24.0 & 26.0 \\
\hline 30 & 13.7 & 17.4 & 23.3 & 27.9 & 32.5 & 35.2 & 38.6 \\
\hline 45 & 14.8 & 19.1 & 26.4 & 32.2 & 38.1 & 41.5 & 45.9 \\
\hline 60 & 15.3 & 19.9 & 28.1 & 34.7 & 41.4 & 45.3 & 50.3 \\
\hline 90 & 16.3 & 21.6 & 30.9 & 38.3 & 45.9 & 50.4 & 56.0 \\
\hline 120 & 17.9 & 22.8 & 32.7 & 40.9 & 49.3 & 54.2 & 60.4 \\
\hline 180 & 20.0 & 26.4 & 35.6 & 42.6 & 49.6 & 53.8 & 59.0 \\
\hline 360 & 25.4 & 33.8 & 40.5 & 45.2 & 49.7 & 52.4 & 55.7 \\
\hline 720 & 31.8 & 39.9 & 48.1 & 54.0 & 59.9 & 63.3 & 67.6 \\
\hline 1080 & 36.4 & 45.5 & 55.6 & 63.1 & 70.4 & 74.7 & 80.1 \\
\hline 1440 & 39.9 & 48.1 & 60.9 & 71.0 & 81.1 & 87.0 & 94.5 \\
\hline 2160 & 45.2 & 53.7 & 68.3 & 79.9 & 91.7 & 98.6 & 107.4 \\
\hline 2880 & 48.1 & 55.7 & 74.0 & 89.7 & 106.1 & 115.8 & 128.1 \\
\hline 4320 & 49.0 & 62.5 & 83.0 & 98.9 & 114.9 & 124.3 & 136.2 \\
\hline
\end{tabular}

Table 4. Theoretical rainfall amounts determined on the basis of measurement data from 1968-2017.

\begin{tabular}{|c|c|c|c|c|c|c|c|}
\hline$t, \min$ & U & $\begin{array}{l}\text { II } \\
u\end{array}$ & $\begin{array}{l}10 \\
11 \\
0\end{array}$ & $\underset{\text { UI }}{\stackrel{\theta}{\text { II }}}$ & $\begin{array}{l}\text { đิ } \\
\text { II }\end{array}$ & $\begin{array}{l}\text { लि } \\
\text { II } \\
u\end{array}$ & $\begin{array}{l}8 \\
\text { II } \\
0\end{array}$ \\
\hline 5 & 6.3 & 7.5 & 9.4 & 10.9 & 12.5 & 13.4 & 14.5 \\
\hline 10 & 8.7 & 10.7 & 13.8 & 16.3 & 18.8 & 20.3 & 22.1 \\
\hline 15 & 10.0 & 13.3 & 17.7 & 21.1 & 24.5 & 26.5 & 29.0 \\
\hline 30 & 13.6 & 17.6 & 23.8 & 28.6 & 33.4 & 36.3 & 39.8 \\
\hline 45 & 14.9 & 19.5 & 26.9 & 32.7 & 38.5 & 41.9 & 46.2 \\
\hline 60 & 15.5 & 20.7 & 28.6 & 34.8 & 41.0 & 44.6 & 49.2 \\
\hline 90 & 16.8 & 21.9 & 31.3 & 38.9 & 46.7 & 51.2 & 57.0 \\
\hline 120 & 18.8 & 23.9 & 33.1 & 40.5 & 48.1 & 52.5 & 58.2 \\
\hline 180 & 21.5 & 26.9 & 36.0 & 43.2 & 50.5 & 54.8 & 60.2 \\
\hline 360 & 25.6 & 35.4 & 41.5 & 45.6 & 49.7 & 52.0 & 54.9 \\
\hline 720 & 34.5 & 39.9 & 49.5 & 57.2 & 65.1 & 69.7 & 75.5 \\
\hline 1080 & 38.7 & 44.8 & 56.5 & 66.0 & 75.7 & 81.5 & 88.7 \\
\hline 1440 & 40.1 & 48.5 & 61.2 & 71.1 & 81.1 & 86.9 & 94.3 \\
\hline 2160 & 45.2 & 53.1 & 67.6 & 79.3 & 91.2 & 98.3 & 107.2 \\
\hline 2880 & 48.1 & 57.9 & 75.3 & 89.2 & 103.4 & 111.8 & 122.4 \\
\hline 4320 & 48.8 & 62.9 & 83.3 & 98.9 & 114.6 & 123.8 & 135.4 \\
\hline
\end{tabular}

In order to compare the obtained results, the percentage differences (Table 5) between rainfall amounts from Table 3 and 4 were calculated. In order to increase the transparency of the results, differences equal to or greater than $5 \%$ are marked in green.

In the case of 22 results (out of 122), there was an increase in rainfall amounts by at least $5 \%$, with as much as 18 times for the frequency of occurrence of $C=10$ years and higher. The highest increase was reported for short-term rainfall ( $t=5, t=10$ and $t=15$ minutes) and lasting 12 and 18 hours. 
Table 5. The percentage change in the rainfall amount.

\begin{tabular}{|c|c|c|c|c|c|c|c|}
\hline$t, \min$ & ü & $\overbrace{}^{\prime \prime}$ & ن & $\underset{U}{\stackrel{2}{I I}}$ & $\begin{array}{l}\text { Iี } \\
\text { II }\end{array}$ & $\begin{array}{l}\text { लि } \\
\text { II }\end{array}$ & $\begin{array}{l}\text { in } \\
\text { II } \\
\text { un }\end{array}$ \\
\hline 5 & -1.6 & -3.3 & 1.6 & 5.3 & 8.4 & 10.1 & 11.9 \\
\hline 10 & -2.2 & -1.1 & 2.1 & 4.1 & 5.7 & 6.4 & 7.3 \\
\hline 15 & 0.0 & -2.2 & 2.8 & 6.1 & 8.8 & 10.1 & 11.6 \\
\hline 30 & -0.7 & 0.9 & 2.0 & 2.6 & 2.9 & 3.1 & 3.2 \\
\hline 45 & 0.7 & 2.6 & 2.1 & 1.6 & 1.1 & 0.9 & 0.7 \\
\hline 60 & 1.3 & 4.0 & 1.8 & 0.3 & -1.0 & -1.5 & -2.2 \\
\hline 90 & 3.1 & 1.6 & 1.4 & 1.5 & 1.6 & 1.6 & 1.7 \\
\hline 120 & 5.0 & 4.5 & 1.0 & -0.9 & -2.4 & -3.1 & -3.8 \\
\hline 180 & 7.5 & 1.9 & 1.2 & 1.4 & 1.7 & 1.8 & 2.0 \\
\hline 360 & 0.8 & 4.8 & 2.5 & 1.0 & -0.1 & -0.8 & -1.5 \\
\hline 720 & 8.5 & -0.1 & 2.9 & 5.9 & 8.7 & 10.1 & 11.8 \\
\hline 1080 & 6.3 & -1.5 & 1.6 & 4.7 & 7.5 & 9.0 & 10.7 \\
\hline 1440 & 0.5 & 0.7 & 0.4 & 0.2 & 0.0 & -0.1 & -0.2 \\
\hline 2160 & 0.0 & -1.2 & -1.0 & -0.8 & -0.5 & -0.3 & -0.2 \\
\hline 2880 & 0.0 & 3.9 & 1.7 & -0.5 & -2.5 & -3.4 & -4.4 \\
\hline 4320 & -0.4 & 0.6 & 0.3 & 0.0 & -0.3 & -0.5 & -0.6 \\
\hline
\end{tabular}

The conducted comparative analysis showed no case of a significant (greater than 5\%) decrease in precipitation amounts.

\section{Conclusions}

The aim of this paper is an attempt to answer the question whether it is necessary to update the probabilistic model of heavy rainfall with the passage of time.

Based on the IMWM-NRI measurement data, the probabilistic models of maximum rainfall were developed. The models were based on the generalized exponential distribution (GED), whose parameters were determined by the maximum likelihood method. The models were developed on the basis of 50-year measurement series from 1960-2009 and 1968-2017. The developed models allow determining the forecasted maximum rainfall amount with given durations from $t=$ 5 to $t=4320$ minutes and frequencies of occurrence from $C=1$ to $C=50$ years.

The analysis showed that heavy rainfall recorded in recent years can significantly affect the depth-durationfrequency (DDF) model. In the case of $18 \%$ of results, there was an increase in precipitation amounts by at least $5 \%$ - especially for the frequency of occurrence $C=10$ years and higher. The highest increase was recorded for short-term rainfall ( $t=5, t=10$ and $t=15$ minutes) and lasting 12 and 18 hours.

The conducted comparative analysis showed no case of a significant (greater than 5\%) decrease in precipitation amounts for the analyzed durations from $t=$ 5 to $t=4320$ minutes and frequencies of occurrence from $C=1$ to $C=50$ years.

The obtained results confirm the observations in the literature on increasing the intensity of rainfall over the last decades. Therefore, there are premises for updating the maximum precipitation models developed in the past, as well as attempt to develop prognostic models taking into account the described trends of changes.

\section{References}

1. T. G. Schmitt, M. Thomas, KA - Wasserwirtschaft, Abwasser, Abfall 47, 1 (2000)

2. M. Zawilski, A. Brzezińska, Urban Water Journal, 11, 7 (2014)

3. A. Kotowski, K. Wartalska, M. Nowakowska, Ochrona Środowiska 38, 1 (2016)

4. S. Y. Park, K. W. Lee, I. H. Park, S. R. Ha, Desalination 226, 1-3 (2008)

5. A. Kotowski, B. Kaźmierczak, J. Hydrometeorology. 14, 6, 1958-1965 (2013)

6. A. Hoy, S. Hänsel, P. Skalak, Z. Ustrnul, O. Bochníček, Int. J. Climatol. 37, 943-962 (2017)

7. B. Kaźmierczak, A. Kotowski, J. of Hydrology. 525, 345-351 (2015)

8. B. Kaźmierczak, M. Wdowikowski, Period. Polytech. Civil Eng. 60, 2, 305-312 (2016)

9. E. Bogdanowicz, J. Stachý, Maximum rainfall in Poland. Design characteristics (The Publishing House of the Institute of Meteorology and Water Management, Warsaw, 1998)

10. S. Coles, An introduction to statistical modeling of extreme values (Springer Series in Statistics, SpringerVerlag, London, 2001)

11. M. Wdowikowski, B. Kaźmierczak, O. Ledvinka, Meteorology Hydrology and Water Management 4, 1, 53-63 (2016)

12. R.D.Gupta, D. Kundu, J. Statistic. Plann. Inference 137, 3537-3547 (2007) 